\title{
Erratum
}

\section{No stress, no pitch accent, no prosodic focus: the case of Ambonese Malay - ERRATUM}

\section{Raechel Maskikit-Essed Carlos Gussenhoven}

doi: 10.1017/S0952675716000154, first published online by Cambridge University Press, 4 October 2016.

An error was introduced in example (1) during the typesetting process. The correct version is given below.
(1) a. ... ma ma ma $\left.\left.)_{\omega}\right)_{\varphi}\right)_{l}$

$$
\mathrm{H}^{*}+\mathrm{L}
$$
b. ... ma ma ma) $\left.\left.)_{\omega}\right)_{\varphi}\right)_{l}$
$\mathrm{H}^{*} \mathrm{~L} \%$
c. ... ma ma ma $\left.\left.)_{\omega}\right)_{\varphi}\right)_{l}$ H\% L\%
d. ... ma ma ma $\left.\left.)_{\omega}\right)_{\varphi}\right)_{l}$
$\mathrm{HL} \%$

In addition, the second sentence of $\$ 3.4$ should read as follows:

We found no effect of prefinal lengthening on the penultimate syllable, nor was the penultimate syllable longer than might be expected if it had stress.

\section{REFERENCE}

Maskikit, Raechel \& Carlos Gussenhoven (2016). No stress, no pitch accent, no prosodic focus: the case of Ambonese Malay. Phonology 33. 353-389. 